\title{
Refractory hypoglycemia in a patient with functional adrenal cortical carcinoma
}

\author{
Katia Regina Marchetti1, Maria Adelaide Albergaria Pereira2, Arnaldo Lichtenstein' \\ and Edison Ferreira Paiva'
}

1Department of General Medicine, and 2Department of Endocrinology, Clinics Hospital, University of Sao Paulo School of Medicine, Sao Paulo, SP, Brazil
Correspondence

should be addressed

to E F Paiva

Email

paiva.edison@gmail.com

\section{Summary}

Adrenacarcinomas are rare, and hypoglycemic syndrome resulting from the secretion of insulin-like growth factor II (IGF-II) by these tumors have been described infrequently. This study describes the case of a young woman with severe persistent hypoglycemia and a large adrenal tumor and discusses the physiopathological mechanisms involved in hypoglycemia. The case is described as a 21-year-old woman who presented with 8 months of general symptoms and, in the preceding 3 months, with episodes of mental confusion and visual blurring secondary to hypoglycemia. A functional assessment of the adrenal cortex revealed ACTH-independent hypercortisolism and hyperandrogenism. Hypoglycemia, hypoinsulinemia, low C-peptide and no ketones were also detected. An evaluation of the GH-IGF axis revealed GH blockade (0.03; reference: up to $4.4 \mathrm{ng} / \mathrm{mL})$, greatly reduced IGF-I levels $(9.0 \mathrm{ng} / \mathrm{mL}$; reference: $180-780 \mathrm{ng} / \mathrm{mL})$, slightly reduced IGF-II levels (197 ng/mL; reference: $267-616 \mathrm{ng} / \mathrm{mL}$ ) and an elevated IGF-II/IGF-I ratio (21.9; reference: 3). CT scan revealed a large expansive mass in the right adrenal gland and pulmonary and liver metastases. During hospitalization, the patient experienced frequent difficult-to-control hypoglycemia and hypokalemia episodes. Octreotide was ineffective in controlling hypoglycemia. Due to unresectability, chemotherapy was tried, but after 3 months, the patient's condition worsened and progressed to death. In conclusion, our patient presented with a functional adrenal cortical carcinoma, with hyperandrogenism associated with hypoinsulinemic hypoglycemia and blockage of the GH-IGF-I axis. Patient's data suggested a diagnosis of hypoglycemia induced by an IGF-II or a large IGF-II-producing tumor (low levels of GH, greatly decreased IGF-I, slightly decreased IGF-II and an elevated IGF-II/IGF-I ratio).

\section{Learning points:}

- Hypoglycemyndrome resulting from the secretion of insulin-like growth factor II (IGF-II) by adrenal tumors is a rare condition.

- Hypoinsulinemic hypoglycemia associated with hyperandrogenism and blockage of the GH-IGF-I axis suggests hypoglycemia induced by an IGF-II or a large IGF-II-producing tumor.

- Hypoglycemia in cases of NICTH should be treated with glucocorticoids, glucagon, somatostatin analogs and hGH.

\section{Background}

This paper describes an unusual presentation of a patient with a functional adrenal cortical carcinoma, with hyperandrogenism associated with hypoinsulinemic hypoglycemia and blockage of the GH-IGF-I axis.
Patient's data suggested a diagnosis of hypoglycemia induced by an IGF-II or a large IGF-II-producing tumor (low levels of GH, greatly decreased IGF-I, slightly decreased IGF-II and an elevated IGF-II/IGF-I ratio). 
Table 1 Measurements of blood glucose levels at baseline, after infusion of the glucose suspension and after the administration of glucagon to correct hypoglycemia.

\begin{tabular}{l}
\hline Time point \\
\hline Basal \\
Suspension of glucose solution \\
$60 \mathrm{~min}$ \\
Intravenous administration of glucagon \\
$20 \mathrm{~min}$ \\
$20 \mathrm{~min}$ \\
$30 \mathrm{~min}$
\end{tabular}

\section{Case presentation}

A 21-year-old black woman had presented 8 months prior to the described events with bloating, weakness, lack of appetite, nausea, weight loss, dyspnea and edema of the lower limbs. In the preceding 3 months, her general condition had worsened, and she experienced episodes of mental confusion and visual blurring secondary to glycemia of approximately $30 \mathrm{mg} / \mathrm{dL}$. Initial findings included BP of $150 / 90 \mathrm{mmHg}$, HR $126 \mathrm{bpm}$, weight $72 \mathrm{~kg}$, height $164 \mathrm{~cm}$, BMI $26.8 \mathrm{~kg} / \mathrm{m}^{2}$, diffuse xerosis, cushingoid facies, acne in the frontal and chest regions, hyperchromic spots in the frontal region, increased facial and chest hair and grade 2 cervical acanthosis. There was an absence of buffalo hump, swelling of the supraclavicular fossa, abdominal striae and skin bruising. A mass of stony consistency was detected on the patient's right side.

\section{Investigation}

An overall laboratory assessment produced the following findings: 13,920leukocytes/mL $\quad(72.0 \%$ neutrophils and $0 \%$ eosinophils); $\mathrm{Na}=141 \mathrm{mEq} / \mathrm{L}$ (135-145 mEq/L); K=2.7 mEq/L (3.5-5 mEq/L); serum albumin $=2.5 \mathrm{~g} / \mathrm{dL} \quad(3.4-4.8 \mathrm{~g} / \mathrm{dL}) ; \quad$ gamma-glutamyl transferase $(\mathrm{GGT})=212 \mathrm{U} / \mathrm{L}(5-36 \mathrm{U} / \mathrm{L})$ and metabolic alkalosis $(\mathrm{pH}=7.56$ and bicarbonate $=32 \mathrm{mmol} / \mathrm{L})$. A functional assessment of the adrenal cortex revealed ACTH-independent hypercortisolism and hyperandrogenism (serum cortisol=44.2 $(5-25 \mu \mathrm{g} / \mathrm{dL})$; urinary cortisol $=1.097 \quad(50-310 \mu \mathrm{g} / 24 \mathrm{~h})$; $\quad$ salivary cortisol at $24 \mathrm{~h}=0.93 \quad(<0.12 \mu \mathrm{g} / \mathrm{dL})$; androstenedione $=3.14 \quad(<2.2 \mathrm{ng} / \mathrm{mL}) ; \quad$ testosterone $=106$ $(<48 \mathrm{ng} / \mathrm{dL}) ;$ dehydroepiandrosterone sulfate $=5.920$ (1.480-4.870 ng/mL); adrenocorticotropic hormone $<2 \quad(7.2-63.3 \mathrm{pg} / \mathrm{mL}))$. A hypoglycemia assessment conducted an hour after the infusion of a $50 \%$ glucose suspension revealed glucose of $33 \mathrm{mg} / \mathrm{dL}$, insulin $<0.6 \mathrm{U} / \mathrm{mL}$, C-peptide $<0.3 \mathrm{mg} / \mathrm{mL}$ and no ketones; hypoglycemia was corrected via the administration of glucagon (Table 1). An evaluation of the GH-IGF axis revealed GH blockade (0.03; reference, up to $4.4 \mathrm{ng} / \mathrm{mL})$, greatly reduced IGF-I levels $(9.0 \mathrm{ng} / \mathrm{mL}$; reference, 180-780 ng/mL), slightly reduced IGF-II levels (197 ng/mL; reference, 267-616 ng/mL) and an elevated IGF-II/IGF-I ratio (21.9; reference, $\sim 3$ ).

An abdominal CT scan revealed a large, heterogeneous expansive mass in the right adrenal gland $\left(15.0 \times 15.0 \times 14.0 \mathrm{~cm}^{3}\right)$ that was in contact with the right kidney and the right liver lobe, with no signs of invasion. The liver was increased in size, with multiple hypervascularized nodules (Fig. 1). A chest CT scan revealed multiple bilateral pulmonary nodules compatible with metastases.

A liver biopsy permitted a diagnosis of a poorly differentiated carcinoma, with an immunohistochemical profile compatible with adrenal cortical carcinoma (negative for cytokeratin 7, Hep Par 1, 35BH11, PAX-8, TTF-1 and chromogranin but positive for inhibin and vimentin).

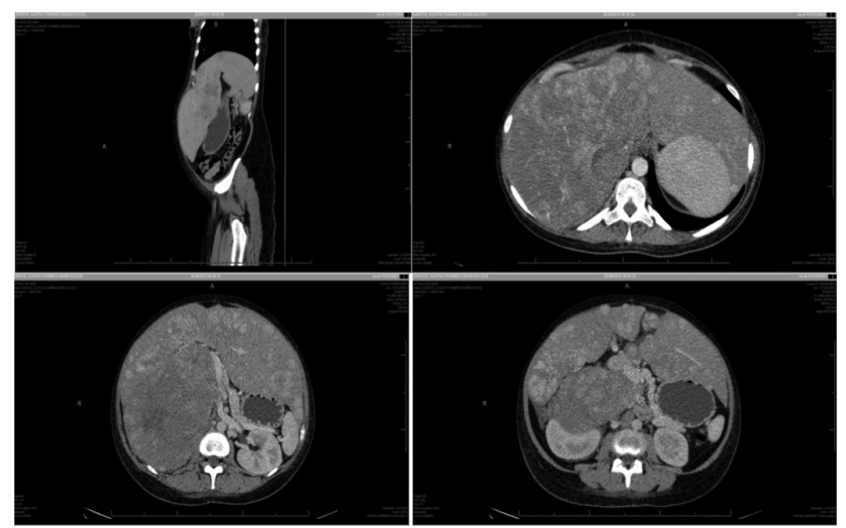

Figure 1

CT scans of the abdomen and pelvis, revealing a large mass on the right adrenal gland (arrow) and multiple liver nodules suggestive of secondary lesions. 


\section{Treatment}

During hospitalization, the patient experienced frequent hypoglycemic episodes and exhibited difficult-to-control hypokalemia despite the intravenous administration of potassium and hypertonic glucose. The introduction of octreotide was ineffective at controlling hypoglycemia. A combination of enalapril, spironolactone, amlodipine and hydralazine was required to control hypertension. Due to the unresectability of her tumor, the patient underwent 2 cycles of chemotherapy. The first cycle included cisplatin, etoposide, doxorubicin, and mitotane, whereas the second cycle involved cisplatin; no response to either regimen was observed. After 3 months, the patient's condition worsened and progressed to death.

\section{Outcome and follow-up}

No response to either chemotherapy regimen was observed. After 3 months, the patient's condition worsened and progressed to death.

\section{Discussion}

Hypoglycemia in non-diabetic patients may be attributable to the hypersecretion of insulin or related peptides, a lack of counter-regulatory hormones, the failure of organs involved in the endogenous production of glucose or serious diseases. Noninsulinoma tumor-associated hypoglycemia can be secondary to neoplasms that produce IGF-II or big IGF-II, also known as non-islet-cell tumors (NICTHs) or IGF-II-omas $(1,2,3,4)$. Such neoplasms are generally solid tumors of unknown prevalence, although they are rarer than insulinomas. Among NICTH, 45\%, $23 \%, 10 \%$ and $8 \%$ are mesenchymal, hepatic, adrenal, and gastrointestinal respectively. Relatively rarely, NICTHs have been described in cases involving leukemia, lymphoma and/or pheochromocytoma (3).

In normal individuals, most of the circulating IGF-II is in the form of a $7.5 \mathrm{kDa}$ peptide. In patients with NICTH, a higher percentage of IGF-II can circulate as a precursor of an $11-18 \mathrm{kDa}$ molecule known as big IGF-II (5). IGF-II has insulin-like effects, and its interaction with insulin receptors increases glucose uptake in muscles and decreases liver glycogenolysis and neoglucogenesis, causing hypoglycemia. In fatty tissue, lipolysis is decreased, leading to the increased supply of fatty acids and glycerol, known substrates of ketogenesis and neoglucogenesis, resulting in glycogen accumulation and the worsening of hypoglycemia. Blockage of the pancreatic secretion of insulin and glucagon is also observed. Normally, the binding of IGF-II to plasma proteins prevents this factor from passing through the capillary barrier and therefore precludes the aforementioned effects. However, because big IGF-II does not bind correctly to protein carriers, it easily crosses the capillary barrier and fully exerts its insulin-like effects $(4,5)$. Therefore, in NICTH, the hypoglycemia is associated with low insulin levels but blocked ketones and positive responses to glucagon (6). The effects of big IGF-II on the insulin receptor also promote the intravascular to intracellular transport of potassium (7).

When interacting with IGF-I receptors, IGF-II blocks the pituitary secretion of $\mathrm{GH}$, decreasing the production of IGF-I by the liver. This change in the GH-IGF axis increases sensitivity to insulin and decreases the levels of IGF carrier proteins, increasing the availability of free IGF-II, expanding its hypoglycemic effects and potentially leading to hypokalemia. Thus, patients with NICTH have hypoglycemia with hypoinsulinemia, low C-peptide levels, decreased IGF-I and variable IGF-II, with an elevated IGF-II/IGF-I ratio (7).

A multicenter prospective observational study that included 78 patients from 67 centers described the characteristics of NICTH (7). The most frequent initial manifestation was weight loss associated with an abdominal mass and pain (52\%), followed by hypoglycemia (48\%). In this study, 30\%, $12 \%$ and $7 \%$ of NICTH were hepatocarcinomas, gastric carcinomas and mesotheliomas respectively (with adrenal tumors accounting for $1.2 \%$ of the NICTH). All patients presented with low IGF-I; 39\% of patients were positive for big IGF-II (42\% exhibited increased free IGF-II and 93\% of these patients had an elevated IGF-II/IGF-I ratio). In 90\%, serum insulin was $<6 \mu \mathrm{g} / \mathrm{mL}$. Hypoglycemia associated with hypokalemia occurred in $53 \%$ of cases. There was a significant reduction in big IGF-II and the resolution of hypoglycemia after tumor resection. Thus, it can be concluded that in the diagnosis of NICTH, the suppression of IGF-I and an increase in the IGF-II/IGF-I ratio are more important than the detection of elevated big IGF-II (7).

Our patient presented with a functional adrenal cortical carcinoma, with Cushing's syndrome and hyperandrogenism associated with hypoinsulinemic hypoglycemia and blockage of the GH-IGF-I axis. The data suggest a diagnosis of hypoglycemia induced by an IGF-II- or big IGF-II-producing tumor (low levels of $\mathrm{GH}$, greatly decreased IGF-I, slightly decreased IGF-II and an elevated IGF-II/IGF-I ratio). Because the tumor was unresectable, pharmacological treatment was administered. The hypoglycemia in cases of NICTH 
is treated with glucocorticoids (8) or with glucagon (9), somatostatin analogs and hGH (9). Due to the hypercortisolism, somatostatin analog was administered, although unsuccessfully, followed by chemotherapy treatment, which also produced no response.

\section{Declaration of interest}

The authors declare that there is no conflict of interest that could be perceived as prejudicing the impartiality of the research reported.

\section{Funding}

This research did not receive any specific grant from any funding agency in the public, commercial or not-for-profit sector

\section{Author contribution statement}

All authors have assisted the patient during admission. Katia Regina Marchetti made the first draft and all the other authors made suggestions to improve the text. Edison Ferreira Paiva assisted with the final version.

\section{References}

1 Libé R 2015 Adrenocortical carcinoma (ACC): diagnosis, prognosis, and treatment. Frontiers in Cell and Developmental Biology 345 (doi:10.3389/fcell.2015.00045)

2 Ishikura K, Takamura T \& Takeshita Y 2010 Cushing's syndrome and big IGF-II associated hypoglycaemia in a patient with adrenocortical carcinoma. BMJ Case Report 2010. (pii: bcr07.2009.2100) (doi:10.1136/ bcr.07.2009.2100)

3 Egughi T, Tokuyama A \& Tanaka Y 2001 Hypoglycemia associated with the production of insulina-like growth factor II in adrenocortical carcinoma. Internal Medicine 40 759-763. (doi:10.2169/ internalmedicine.40.759)

4 Daughaday WH, Emanuele MA, Brooks MH, Barbato AL, Kapadia M \& Rotwein P 1988 Synthesis and secretion of insulin-like growth factor II by a leiomyosarcoma with associated hypoglycemia. New England Journal of Medicine 319 1434-1440. (doi:10.1056/NEJM198812013192202)

5 Miraki-Moud F, Grossman AB, Besser M, Monson JP \& Camacho-Hubner C 2005 A rapid method for analyzing serum proinsulin-like growth factor-II in patients with non-islet cell tumor hypoglycemia. Journal of Clinical Endocrinology and Metabolism 90 3819-3823. (doi:10.1210/jc.2004-2090)

6 Dynkevich Y, Rother KI, Whitford I, Qureshi S, Galiveeti S, Szulc AL, Danoff A, Breen TL, Kaviani N, Shanik MH, et al. 2013 Tumors, IGF-2, and hypoglycemia: insights from the clinic, the laboratory, and the historical archive. Endocrine Reviews 34 798-826. (doi:10.1210/ er.2012-1033)

7 Fukuda I, Hizuka N, Ishikawa Y, Yasumoto K, Murakami Y, Sata A, Morita J, Kurimoto M, Okubo Y \& Takano K 2006 Clinical features of insulin-like growth factor-II producing non-islet-cell tumor hypoglycemia. Growth Hormone and IGF Research 16 211-216. (doi:10.1016/j.ghir.2006.05.003)

8 Teale JD \& Marks V 1998 Glucocorticosteroid therapy suppresses abnormal secretion of big IGF-II by non-islet cell tumours inducing hypoglycaemia. Clinical Endocrinology 49 491-498. (doi:10.1046/ j.1365-2265.1998.00564.x)

9 Teale JD \& Wark G 2004 The effectiveness of different treatment options for non-islet cell tumor hypoglycaemia Clinical Endocrinology 60 457-460. (doi:10.1111/j.13652265.2004.01989.x)

Received in final form 27 September 2016

Accepted 19 October 2016 